\title{
LITERATURAS DE LA CERTEZA Y DE LA DUDA ONTOLÓGICA. PROPUESTA CLASIFICADORA PARA LA FICCIÓN DISTANCIADA
}

\author{
Alejo Gabriel Steimberg \\ Universidad de Extremadura \\ alejosteimberg@gmail.com
}

Recibido: 23-01-2013

Aceptado: 30-04-2013

(c) $10 \Theta$

RESUMEN

El establecimiento de macrocategorías resulta de suma utilidad para el estudio de las literaturas de género. El grado de alejamiento del mundo «real» o empírico y la forma en que este alejamiento se lleva a cabo ya han sido señalados como parámetros de clasificación. En este artículo proponemos que la presencia o ausencia de duda ontológica en términos intradiegéticos permite también echar luz sobre las relaciones entre los diferentes tipos «ficción distanciada», un taxón que incluye tanto la literatura fantástica como la ciencia ficción y lo maravilloso, es decir aquellas formas literarias alejadas de la mímesis.

Palabras Clave: ficción distanciada, fantástico, fantasy, ciencia ficción, estrés ontológico

ABSTRACT

In genre theory, macrocategories have been established in order to clarify the relations between different literary forms, the degree and nature of the estrangement from the actual world being some of the parameters used for the classification. Here we propose the conceptual couple ontological certainty/ontological doubt as a way to further analyse and compare science-fiction, fantasy and fantastic literature as forms of «estranged fiction».

KEYWORDS: estranged fiction, fantastic literature, fantasy, science-fiction, ontological stress 


\section{EL CONCEPTO DE GÉNERO}

Fantástico, fantasy, ciencia ficción... Las formas literarias mencionadas requieren comenzar por una noción indispensable: se trata, por supuesto, de la noción de género. Karl Viëtor (1986: 10), en «L'histoire des genres littéraires», su artículo de comienzos de la década de 1930, señalaba algo que ha sido una constante en la historia del término: su uso para definir categorías de especificidad variable. En efecto, se había hablado de género tanto para la epopeya, la poesía lírica y el drama, como para la comedia y la oda. La propuesta de Viëtor para evitar esta confusión — que es el punto de vista que se impondrá más tarde- se aleja de la opción privilegiada por las ciencias naturales, en las que «género» se aplica a la unidad más amplia, y «especie» al subgrupo. Viëtor prefiere, por el contrario, llamar «géneros» a los elementos de la segunda categoría. Los macrogéneros como la epopeya, la poesía lírica y el drama constituyen por su lado las «actitudes fundamentales» para el abordaje de la creación poética. ${ }^{1}$ Por último, Viëtor (1986: 34) no deja de señalar el carácter siempre transitorio de toda historia de los géneros, debido al carácter de objetos culturales cambiantes («vivos») de los géneros. Por ello, podría agregarse, siempre conviene sumar al criterio formal taxonómico una mirada a la historia concreta de la denominación en cuestión y de sus referentes; esto es, a qué obras se ha considerado como formando parte o no de un género dado. Esta idea también la señalará Robert Scholes (1986), que propondrá una teoría superadora.

Para Scholes (1986: 77-78) la idea de una poética de la ficción es en sí un concepto genérico: al aceptarla aceptamos también que la ficción no funciona de la misma manera que, por ejemplo, la poesía lírica, y que la literatura de imaginación en su conjunto no funciona igual que otras construcciones verbales. Buscar establecer una poética distintiva para la ficción implica percibirla, de hecho, como un género distinto (un macrogénero, podríamos añadir; Scholes propondrá luego otra denominación).

Scholes (1986: 80-81) busca proponer una teoría integradora, una teoría de tipos ideales a la que llamará «teoría de los modos», reservando el término de «género» al estudio de obras individuales consideradas desde el punto de vista de su relación con tradiciones específicas e históricamente identificables. El presupuesto básico de esta teoría es que todas las obras de ficción son re-

1 Este concepto se relaciona con la idea de Naturformen de Goethe (1957: 1016). En la misma línea, Northrop Frye (1957: 13) hablará de radicals of presentation y Claudio Guillén (2005: 156) de cauces de presentación. Estas «actitudes fundamentales» serán llamadas modos por muchos otros autores, entre ellos Fredric Jameson (1981: 141) y, como veremos también, Robert Scholes (1986). 
ductibles a tres «tonos» fundamentales; modos ficcionales básicos que se basan a su vez en los tres tipos de relaciones posibles entre el mundo ficcional y el mundo de la experiencia. Un mundo ficcional — continúa Scholes- puede ser igual, mejor o peor que el mundo de la experiencia; esos diferentes tipos de mundos ficcionales implican actitudes que se suelen llamar románticas, ${ }^{2}$ satíricas o realistas, según se trate del mundo heroico del romance, del decadente de la sátira o del mimético de la historia. Scholes (1986: 82) declina y sitúa a partir de estos tres puntos básicos de referencia toda una serie de formas de la novela, hasta formar el diagrama siguiente:

\section{Sátira $\mid$ Picaresca $\mid$ Comedia $\mid$ Historia $\mid$ Sentimental $\mid$ Tragedia | Romance}

Salvo la sección del esquema ocupada por la Historia, el resto corresponde a formas de la novela, así que puede considerarse que la novela trágica y la sentimental son dos formas del modo del romance, mientras que la picaresca y la novela cómica pertenecerían al modo satírico. La superioridad o inferioridad del mundo construido proviene de los seres que lo pueblan (1986: 83): superhombres en un mundo ideal para el caso del romance, e infrahombres grotescos sumergidos en el caos para la sátira. Los seres heroicos de la tragedia, que viven en un mundo que da un sentido a sus actos, así como los protagonistas de la ficción picaresca, que se enfrentan a un nivel de caos que supera lo que un humano normal soportaría, son personajes más cercanos a nuestro mundo que los del romance y la sátira. Los personajes de la ficción sentimental y de la comedia presentan virtudes y debilidades humanas que el lector puede reconocer como propias.

Para evitar una impresión de estratificación absoluta, y para poder dar cuenta de las combinaciones de los diferentes tipos de universos ficcionales, Scholes (1986: 84) sugiere una modificación a la representación gráfica del esquema, incorporando la dimensión vertical:

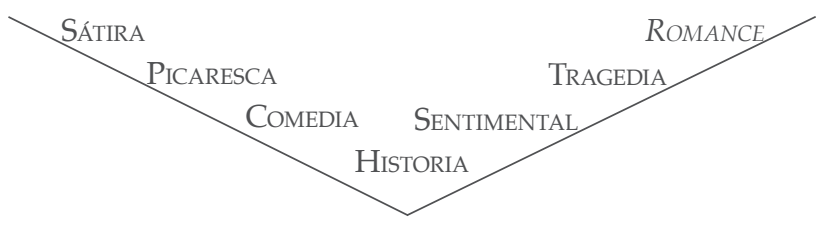

2 Románticas en el sentido de propias del romance, la forma literaria que luego se constituiría en la contracara de la novela realista. Como señalan Antonio García Berrio y Javier Huerta Calvo (1985: 181182), el anglicismo romance puede ser confundido en español con la forma lírico-épica homónima, pero su uso se hace ineludible para referirse a esas formas narrativas específicas. El uso de itálicas permite evitar la confusión. 
La propuesta permite ver en el Realismo, en tanto que técnica ficcional, un debilitamiento de las actitudes propias del romance y la sátira, relacionado con el fortalecimiento del cientificismo y el empirismo (Schole, 1986: 85). Esta evolución —continúa Scholes (1986: 86) — no es sin embargo lineal, ya que el desarrollo de la novela posterior al surgimiento y apogeo del Realismo siguió una dirección diferente, en la línea de una combinación de impulsos más complicada y poderosa: el Naturalismo, en cuyas historias dominaba la alienación y la destrucción. De esta forma, en el siglo XX la ficción siguió alejándose del realismo, a lo largo de una evolución que vería por momentos el estallido de la unidad interna de la novela, inclinada tanto hacia la sátira como hacia el romance (Scholes, 1986: 87 ).

Tanto Scholes como Viëtor, entre muchos otros, aceptan la división básica y tripartita entre tres modos o formas esenciales, que suele atribuirse a Aristóteles, a Platón, a «los griegos» o, de manera más general aún, a «los antiguos»(Genette, 1986: 91-92). Gérard Genette está entre los autores que criticanla atribución de esta división (que él define como propia del Romanticismo) a autores griegos o clásicos, ${ }^{3}$ ya que dicho error histórico estaría en el origen de una confusión teórica. Para aclararla y fundamentar su propuesta al respecto, Genette comienza por explicar el «sistema de géneros» propuesto por Platón y explotado por Aristóteles, ${ }^{4}$ aunque sin dejar de señalar que considera impropio el uso del término (Scholes, 1986: 95). Genette ilustra el sistema aristotélico de géneros por medio del esquema siguiente (Scholes, 1986: 100):

\begin{tabular}{|c|c|c|}
\hline & MODO DRAMÁTICO & MODO NARRATIVO \\
\hline OBJETO SUPERIOR & TRAGEDIA & EPOPEYA \\
\hline OBJETO INFERIOR & COMEDIA & PARODIA \\
\hline
\end{tabular}

Dicho esquema — señala Genette- deja de lado tanto el poema lírico como la distinción platónica entre el modo narrativo puro, ejemplificado por el ditirambo, y el modo mixto, representado por la epopeya (Scholes, 1986: 106). Así, la tríada platónica narrativo/mixto/dramático se ve reemplazada por la pareja aristotélica narrativo / dramático, en la que el modo mixto es entronizado como único modo narrativo posible (Scholes, 1986: 107). Esta reducción deja un espacio vacío, que se pretenderá ocupar luego mediante la postulación de una expresión no representativa; un agrupamiento de todas las formas de poema

3 Genette ya había enunciado esa crítica en su artículo «Genres, 'types', modes» (1977).

4 Platón menciona en La República (1991: 166) la tríada básica lírica, épica, drama. 
no mimético bajo la denominación «poesía lírica» (Scholes, 1986: 111-112). Una vez instalada, la tríada lírico/épico/ dramático dominará la teoría literaria del romanticismo y extenderá su influencia más allá de ésta, pero no sin modificaciones (Scholes, 1986: 120). Efectivamente, es la visión de Schelling, que enuncia la tríada mencionada como una sucesión de géneros dominantes (la reinterpretación romántica del sistema de modos, convertido ahora en sistema de géneros), que se impondrá en los siglos XIX y XX (Scholes, 1986: 124). La división romántica y post-romántica aborda entonces lo lírico, lo épico y lo dramático no como modos de enunciación sino como géneros, cuya definición implica un elemento temático, por pequeño que sea (Scholes, 1986: 140). Una cuestión que se impone, entonces, una vez establecida la idea de género, es si los tres elementos de la tríada pueden seguir siendo considerados formas naturales como proponía Goethe (Scholes, 1986: 141). Genette sostiene que no, y defiende por esta razón la categoría de archigéneros, cada uno de los cuales contiene a su vez un determinado número de géneros empíricos. Todos los subgéneros, géneros o supergéneros —-sostiene Genette- son clases empíricas establecidas por la observación o extrapolación de datos históricos, por lo que carece de sentido afirmar que el «tipo épico» es más ideal o natural que el género «novela» o «epopeya» (Scholes, 1986: 142-144). Genette conserva entonces el concepto de modo para la enunciación, hablando por ejemplo del «modo del relato» (Scholes, 1986: 148).

Por su parte, Jean-Marie Schaeffer (1986: 186-187), en la senda genettiana, suscribe la idea del género como concepto empírico y sostiene su carácter de entidad puramente textual, oponiéndose a las definiciones de lo que denomina teorías ontológicas, que trascienden la textualidad. Las teorías ontológicas, por otra parte, equiparan el texto a un objeto físico, viéndolo como un sistema autónomo cerrado y defendiendo la idea de una lectura inmanente y no referencial (Schaeffer, 1986: 191-192). La superioridad de la lectura «transtextual» frente a la lectura inmanente - afirma Schaeffer- radica en que reinserta el texto en la red textual de la que la lectura inmanente lo aislaba artificialmente; la «genericidad» sería así un aspecto de la transtextualidad (1986: 193-194). La problemática genérica — sigue el autor- puede ser abordada desde dos ángulos diferentes: la idea del género como categoría de clasificación retrospectiva y el concepto de genericidad como función textual. Para preservar la claridad analítica y teórica, propone distinguir genericidad y género, y considerar este último como una pura categoría clasificadora y no arbitraria, en tanto que se centraría en similitudes textuales (Schaeffer, 1986: 199). Dichas similitudes deben bus- 
carse y estudiarse en los diferentes niveles textuales: modal, formal y temátic (Scholes, 1986: 203).

Estos acercamientos, más allá de sus diferencias, ponen en evidencia una serie de factores dignos de consideración a la hora de utilizar la categoría de género y estudiar los fenómenos y los textos relacionados. El primero es la necesidad de la estratificación de las categorías utilizadas, en nombre de la claridad analítica y clasificadora. De esta manera, los géneros quedan incluidos en macrocategorías, que suelen establecerse en función de la relación del mundo de la ficción con el mundo empírico. Esta visión general del panorama es necesaria para el análisis de formas, si se quiere, «bastardas», que bucean en distintos marcos de género.

Un segundo elemento que se desprende de la comparación de los diferentes puntos de vista sobre el género (y por ende, sobre el texto), brevemente resumidos, es la división del texto en diferentes niveles para su análisis. Aunque la inmensa mayoría de los autores pueda coincidir en esto, no sucederá lo mismo con la importancia atribuida a cada nivel en la definición de tal o cual género. $\mathrm{Y}$ es que todo género puede definirse por una serie de rasgos retóricos, temáticos y enunciativos (Steimberg, 1993: 41-42), pero las distintas definiciones no hacen hincapié en el mismo conjunto de rasgos. Así, hay géneros que, desde su nombre mismo, enfatizan el nivel temático («western»), mientras otros privilegian lo pragmático, el efecto que se busca producir en el lector («horror»). Las propuestas de cambio de definición conllevan también, evidentemente, un recorte distinto del corpus incluido, y la focalización de uno solo de los niveles puede impedir la percepción de la presencia de los rasgos de un género $X$ en una obra $Y$ (nadie buscará, por ejemplo, rasgos fantásticos en una novela de ciencia ficción, si se acepta que no hay fantástico sin temática sobrenatural). Disponer de un mapa claro, por muy esquemático que sea, de las relaciones entre los miembros de una misma «familia» de géneros, y concentrarse en los rasgos textuales, se imponen como requisitos para una mirada analítica productiva de las obras pertenecientes a dichas formas literarias.

\section{LAS «LITERATURAS DE LO IMAGINARIO»: ¿UNA CATEGORÍA TEÓRICA OBVIA?}

El concepto de literaturas de lo imaginario (littératures de l'imaginaire) se utiliza, en la teoría y la crítica francófonas, para englobar los géneros más alejados del principio de la mimesis. Pero resulta notable que las definiciones suelen brillar por su ausencia. Roger Bozetto, en Fantastique et Science- Fiction: deux littératures de l'imaginaire (1992), realiza un análisis comparativo de la li- 
teratura fantástica y la ciencia ficción en tanto que «literaturas de lo imaginario», y sin embargo no proporciona una definición del concepto. El panorama se complica todavía más en la teoría en castellano, ya que no existe un consenso, ni siquiera de facto, sobre la denominación de una categoría que agrupe a formas literarias como lo fantástico, la fantasy o la ciencia ficción. Esto no impide percibir, por supuesto, que esas formas comparten una cierta comunidad lectora y, de manera complementaria y relacionada, una identificación comercial (estos libros suelen ocupar el mismo espacio en las librerías). Y de hecho el rasgo común entre ellas no es difícil de identificar: todas postulan mundos en los que, de manera más o menos aislada, aparecen elementos que no tienen lugar en el mundo empírico («real»). De todas maneras, y más allá de que estas formas literarias parezcan pertenecer a una macrocategoría cuya existencia se acepta de manera «natural», la diferencia terminológica entre los diferentes campos lingüísticos de análisis del área tiene sin dudas consecuencias de peso. En efecto, la terminología interlingüística de las «literaturas de lo imaginario» está llena de falsos amigos y de solapamientos (o de ausencias lisas y llanas), ${ }^{5}$ que dificultan enormemente la traducción de conceptos.

Unos de los pocos autores que explicita una definición del concepto es Francis Berthelot (2006: 1), quien divide las literaturas de lo imaginario en tres géneros mayores por orden de aparición histórica: lo maravilloso, lo fantástico y la ciencia ficción. Los tres tendrían en particular una restricción temática: el universo ficcional descrito en cada caso no pretendería constituirse en mímesis del mundo real, sino separarse de él por medio de la introducción de uno o más elementos divergentes que exceden los límites de lo posible en ese mundo. La manera de presentar a estos géneros de Berthelot remite, aunque no lo mencione, a la definición de ficción distanciada acuñada por Darko Suvin (1977: 25). En sus propias palabras:

La fiction peut donc se diviser selon la manière de mettre en lumière les rapports des hommes entre eux, et avec leur environnement. Si cette manière cherche à reproduire fidèlement les textures et les surfaces empiriques reconnues par les sens et par le sens commun, je propose de l'appeler fiction «réaliste». Si, au contraire, on cherche à mettre ces rapports en lumière par la création d'un cadre formel radicalement ou nettement différent - un locus spatio-temporel ou des protagonistes différents, échappant à toute vérification empirique- je propose le terme de fiction distanciée.

5 Para dar un ejemplo, «fantástico» o «fantastique» pueden utilizarse como sustantivo o adjetivo, algo que no sucede en inglés. Esto permite una confusión entre los términos fantasy y fantastic, como en la obra de Rosemary Jackson (1988) Fantasy: The Literature of Subversion. 
Es decir, Suvin propone dividir la ficción según la manera en que las diferentes obras ponen en escena las relaciones de los hombres entre ellos y con el mundo que los rodea. En esto está siguiendo a Northrop Frye, cuya clasificación de las obras literarias sirve de punto de partida a la obra de muchos de los teóricos de lo que Suvin llama «ficción distanciada».

En efecto, en The Anatomy of Criticsm, Northrop Frye (1957: 33-34) propone una clasificación de modos literarios centrada en el «realismo» del héroe, entendiendo por esto su relación con el hombre común. De acuerdo con dicho enfoque, los modos literarios posibles serían cinco: mítico, romance, mimético alto, mimético bajo e irónico. En el modo mítico el héroe es divino o semidivino, su naturaleza es superior tanto a otros hombres como al mundo que los rodea. En el modo del romance es superior en grado a otros hombres y a su medio ambiente; se trata de un héroe identificado como humano, que evoluciona en un mundo en el que las leyes de la naturaleza parecen, en mayor menor medida, suspendidas. El héroe del modo mimético superior es superior en grado a otros hombres pero no al contexto, mientras el del mimético bajo no es superior ni al hombre común ni al contexto. El héroe del modo irónico, por último, es inferior al hombre común y, por ende, al lector. Los modos de Frye se articulan, entre otras categorías, con lo que él llama mythoi y que podríamos, por su combinatoria de rasgos de diferentes niveles, considerar como géneros narrativos: cómico, romance, trágico e irónico. Frye (1957: 186) señala que el romance es la forma literaria más cercana a la fantasía compensatoria (wish-fullfilment dream). Esta observación es interesante, ya que otros autores como Kathryn Hume establecen una relación particular entre el romance y la ficción distanciada. En Fantasy and Mimesis (1984), Kathryn Hume pretende evitar discusiones sobre géneros y otros tipos de categorías, y habla entonces de mimesis y de fantasy como dos impulsos, mimético y antimimético respectivamente, presentes en mayor o medida en toda obra literaria. La definición que proporciona dicha autora es enormemente abarcadora: al definir la fantasy como «any departure from consensus reality» (Hume, 1984: 21), ensancha la categoría hasta hacerla abarcar la totalidad de lo que Suvin llamaba «ficción distanciada». Así es como puede incluir la ciencia ficción dentro de la fantasy, al afirmar que

I would include as a departure from consensus reality some technical or social innovations which have not yet taken place, even though they may well happen in the future: cloning of humans and utopian societies are both examples of this sort of fantasy [...]. I would embrace utopias 
along with allegories and science fiction as having fantastic elements, ${ }^{6}$ and therefore of concern in a study of fantasy (Hume, 984: 21-22) .

Suvin, como ya se dijo, introduce el concepto de novum como rasgo central de la ficción distanciada, caracterizándose cada una de las formas de este tipo de ficción por un tipo particular de novum, o más bien por la relación del mundo de ficción con las reglas del mundo empírico del autor que la introducción de ese novum implica o establece. Así, afirma Suvin, «Le fantastique [...] est un genre qui introduit dans un monde censé être empirique des lois anticognitives. Alors que le conte de fées ignore tout simplement les lois naturelles, le fantastique leur est contraire» (Suvin, 1977: 15-16). A Hume, en cambio, que considera que tanto fantasy como «mimesis» son impulsos más o menos presentes en toda obra literaria, no le interesa establecer categorías de lo que ella llama fantasy sino relacionar este «impulso» con las categorías más generales que ella establece. Es así como identificará cuatro «acercamientos básicos a la realidad» (ilusión, visión, revisión y desilusión), a cada uno de los cuales correspondería un tipo de literatura (Hume, 1984: 55). Como estos tipos literarios pueden presentar elementos tanto miméticos como antimiméticos (que Hume llama, produciendo confusión, fantásticos), es posible encontrar en todos ellos ejemplos de ficción distanciada.

La primer categoría propuesta por Hume es la de «literatura de ilusión», que correspondería a la literatura «escapista» y que presentaría la realidad como algo aburrido, antirromántico (en el sentido vulgar de chato y poco grandioso) o deprimente, ofreciendo en cambio «ilusiones reconfortantes». La «literatura de visión», por su lado, ofrece «un nuevo sentido de realidad, una nueva interpretación que puede parecer más variada o intensa que la nuestra [...]. Las visiones de Vonnegut, Beckett y Kafka toman este acercamiento». También incluye en esta categoría a The Hobbit y obras de ciencia ficción de Arthur Clarke y Ursula K. Le Guin diciendo que esos textos funcionarían como «literatura de visión» aun sin los elementos antimiméticos. La «literatura de revisión», por su parte, propondría planes para revisar la realidad y darle forma a diferentes futuros. Se trataría de una literatura didáctica, divisible a su vez por el tipo de didactismo ofrecido; Perelandra, de C.S. Lewis, sería un caso de didactismo cosmológico, y 1984 (George Orwell) y Brave New World (Aldous Huxley) de didactismo moral. Por último, la «literatura de desilusión», contrariamente a las otras formas, plantearía que la realidad es incognoscible

6 El problema central del acercamiento de Hume es que, al igual que Rosemary Jackson, no establece diferencia alguna entre fantasy y fantastique, lo cual anula la especificidad de las teorías concebidas para una u otra categoría (ya sea la de Todorov, la de Tolkien, etc.). 
y se propondría desmantelar mitos reconfortantes sin ofrecer ningún reemplazo, asumiendo que todas las interpretaciones de la realidad, por incomprobables, carecen de valor.

El concepto de «literatura de ilusión» reviste especial interés para nuestro enfoque, ya que abarcaría géneros enteros de la ficción distanciada. Esta «literatura escapista» incluye para Hume (1984: 58) un abanico de géneros y subgéneros: la pastoral, el relato de aventura y conquista, la novela cómica y formas «afectivas» como la detective story, el thriller y la pornografía. La literatura afectiva, dice Hume (1984: 74), está escrita para producir un efecto específico en la audiencia; esto incluiría el relato fantástico, las historias de fantasmas y la horror story. La existencia de formas literarias en las cuales el efecto pragmático deseado ocupa un lugar central está fuera de toda duda; lo que es menos convincente es que todas esas formas puedan ser consideradas como literatura escapista. La misma Hume señala, por ejemplo, que uno de los efectos buscados por el género fantástico es el de hacernos revisar nuestras nociones de la realidad (1984: 78). Al barrer de un plumazo géneros enteros de la ficción distanciada como el relato fantástico, Hume no hace sino caer en la tradicional separación (axiológica) entre literatura «baja» y «alta». Sólo así puede explicarse que rescate una obra como Through the Looking-glass de Lewis Carroll al decidir considerarla como «literatura de desilusión». Y es que la clasificación de Hume se ve amenazada por dos grandes problemas. Por un lado, la falta de justificación en la atribución de algunas categorías; por el otro, una definición de fantasy que podríamos llamar «superficial»: a Hume le alcanza con la presencia de elementos antimiméticos, independientemente de su función en el texto, que podría ser perfectamente poética o paródica.

Christian Vandendorpe (1993: 254-255), por su parte, busca encuadrar, siguiendo a Suvin, los relatos definibles como «ficción distanciada». Para ello, retoma la clasificación de Frye (1957: 33-34) del tipo de relato de acuerdo al nivel de poder (o falta de él) del protagonista, a la que cruza con el eje racionalidad/irracionalidad. Queda construido así el siguiente cuadro:

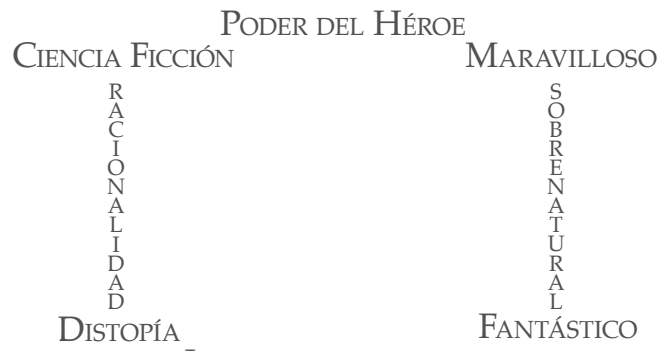

IMPOTENCIA DEL HÉROE 
La explicación que Vandendorpe (1993: 255-256) da a continuación resulta un poco más clara, ya que «ciencia ficción» y «distopía» aparecen como dos variantes de la ciencia ficción: la más tradicional y optimista por un lado, que ilustra todas las posibilidades que la ciencia abre al hombre, y la pesimista, que construye toda una serie de futuros distópicos para la humanidad. De todas formas, la utilidad de este esquema cuadrangular es que permite iluminar relaciones entre tipos literarios poco exploradas. Así, si lo maravilloso y la ciencia ficción suelen ser puestos por diversos autores dentro de los mundos «otros», en el sentido de mundos diferentes al mundo que alberga al lector y al autor de la obra, ${ }^{7}$ es menos común establecer lazos, mediante el análisis de la construcción del relato, entre el género fantástico y un tipo particular de ciencia ficción. Para Vandendorpe, la literatura fantástica y la ciencia ficción distópica tienen en común el hecho de presentar a un protagonista que es víctima del mundo, extraño para el lector, en el que vive. Siguiendo esta línea de análisis, será posible entonces relacionar de manera aún más estrecha el relato fantástico y aquellas obras de ciencia ficción en las que los sufrimientos del protagonista se deben a que el mundo en el que vive se vuelve extraño de repente, en virtud de un acontecimiento que no puede ser explicado por las leyes que se supone que rigen el mundo en que sucede la historia (que es lo que también ocurre en la literatura fantástica). Además de tener en común la impotencia del protagonista, estos dos tipos de relato comparten su duda frente a la naturaleza de los eventos presenciados.

Tratemos ahora una de las más famosas derivaciones de la teoría de los géneros planteada por Frye, la que propuso Tzvetan Todorov. En su célebre Introduction à la littérature fantastique (1970: 49), Todorov presenta una categorización de diversas formas literarias de acuerdo con la manera en que los eventos extraños planteados en el relato se articulan con el mundo de ficción. El diagrama de Todorov es el siguiente:

\begin{tabular}{|c|c|c|c|c|}
\hline EXTRAÑO & FANTÁSTICO-EXTRAÑO & $\begin{array}{c}\text { FANTÁstico } \\
\text { Puro }\end{array}$ & $\begin{array}{c}\text { FANTÁSTICO } \\
\text { MARAVILLOSO }\end{array}$ & MARAVILLOSO \\
\hline
\end{tabular}

La piedra de toque de la clasificación todoroviana es la duda sobre la naturaleza de los eventos sorprendentes: el género fantástico puro existe mientras ésta no se disipe. ${ }^{8}$ Si la explicación finalmente es racional se tratará

7 Es lo que hace, por ejemplo, Neil Cornwell (1990: 39).

8 Numerosos autores concuerdan en que la clave de lo fantástico es que la aparición del elemento en apariencia sobrenatural debe ser presentada forzosamente en el texto como problemática, a falta de lo cual el relato pertenecería más bien al dominio de lo maravilloso. Así Michel Lord (1993: 102), por 
de un relato fantástico-extraño, si es sobrenatural de uno fantástico-maravilloso; si nunca se sale de la lógica «natural» se tratará de un relato extraño, y si por el contrario la lógica dominante es la de lo sobrenatural estaremos frente a un relato maravilloso. La clasificación propuesta por Todorov será retomada por otros autores, que harán algunas correcciones para poder aplicarla a las literaturas de lo imaginario o «ficción distanciada» en general.

Una de las clasificaciones más abarcadoras al respecto es la que propondrá Neil Cornwell (1990: 39), que retoma la clasificación de Todorov (1970: 49) explicando su relación con todas las formas de la ficción distanciada. El esquema global propuesto por Cornwell es el siguiente: ${ }^{9}$

\begin{tabular}{|c|c|c|c|c|c|}
\hline FACTION $^{10}$ & NON-FICTION & REALISM & UNCANNY REALISM & FANTASTIC UNCANNY & $P_{F}$ \\
\hline $\mathrm{PF}$ & \multicolumn{2}{|c|}{ FANTASTIC- MARVELLOUS } & MARVELLOUS & \multicolumn{2}{|l|}{ Mythology, ETC. } \\
\hline
\end{tabular}

El parámetro central de la categorización que Cornwell realiza es el de la distancia con «nuestro» mundo, lo cual justifica aún más el uso del nombre propuesto por Suvin. Las grandes categorías de la ficción distanciada serían entonces lo fantástico-maravilloso, lo maravilloso y lo mitológico. La última categoría no necesita aclaración. La primera, lo «fantástico-maravilloso», incluiría los relatos en que la duda sobre la naturaleza de un evento extraño se termina resolviendo por el lado de lo sobrenatural. Lo maravilloso, por último, es para Cornwell la categoría más amplia, para la que propone a su vez una serie de subdivisiones: 1) What if?, 2) Fairy Story y 3) Romance/Fantasy, que implican un alejamiento progresivo en relación con «nuestro» mundo. La primera división abarca aquellos relatos que incluyen sólo un elemento (o, en todo caso, un número limitado) de lo manifiestamente imposible, e incluiría tanto La metamorfosis de Kafka o El capote de Gogol como aquellas obras de ciencia-ficción que construyen el mundo de la diégesis a partir de una sola infracción a las reglas de nuestro mundo. La segunda, Fairy Story, comprende las narraciones que se desarrollan en nuestro mundo, pero con transformaciones múltiples. Las historias incluidas en la última subdivisión se desarrollan en un mundo manifiestamente «otro». Queda claro, entonces, que la clasifi-

ejemplo, sostiene que un texto no puede ser considerado «fantástico» si no manifiesta, en uno de sus estratos discursivos, alguna forma de resistencia al elemento extraño.

9 La primera parte del diagrama, que interesa menos a los efectos del presente trabajo, da cuenta de las obras literarias en las que el impulso mimético sería el dominante. El punto medio del diagrama, PF (pure fantastic) corresponde a lo «fantástico puro» de Todorov, en el que la duda sobre la naturaleza de los eventos del relato no se resuelve; fantastic uncanny, a los relatos que se inclinan por una explicación racional.

10 «Fictionalised contemporary history and politics» (Cornwell 1990: 39). 
cación de Cornwell, que se propone como una corrección y una ampliación de la de Todorov, categoriza las obras literarias según el grado de distancia existente entre el mundo de la ficción y el mundo de su autor. Lo que se echa en falta en su propuesta, y sí está presente, por ejemplo en la de Suvin, es una consideración cualitativa, y no sólo cuantitativa y progresiva, de la forma en el que el mundo de ficción se aleja de la realidad empírica de su contexto de producción.

A modo de conclusión parcial, podemos señalar que todas las propuestas de los autores nombrados hasta aquí (muchos de los cuales se basan en la concepción de los géneros literarios defendida por Northrop Frye) tienen algo que aportar tanto al análisis de las literaturas de lo imaginario en su conjunto como al de sus diferentes manifestaciones. Así, la teoría de Todorov es la primera en plantear un abordaje estructural a uno de los géneros de lo imaginario, lo fantástico, sentando las bases para un ensanchamiento de este tipo de acercamiento a toda la ficción distanciada. Neil Cornwell, por su parte, lleva a cabo justamente dicha extensión (con modificaciones, por supuesto) de la teoría todoroviana a los otros géneros de lo imaginario. De Hume es interesante la definición de fantasy como un «impulso» homologable a la mímesis que es, por ende, una categoría transgenérica. Por su parte, los conceptos de Suvin de novum y de «ficción distanciada» resultan capitales para introducir importantísimas distinciones que permitan poner en evidencia singularidades de cada género que pasarían desapercibidas en una simple clasificación cuantitativa de la distancia de cada uno con el mundo «real».

Por el momento, nos es posible ya proponer un esquema de la ficción distanciada basado en el de Vandendorpe (1993: 254-255), pero reemplazando el eje poder/impotencia del héroe por otro que vaya de la certeza a la duda ontológica, en el que la equivalencia de una díada similar a la de fantástico/ fantasy del lado filo-científico de la ficción distanciada quede más en evidencia. El esquema resultante sería el siguiente:

CERTEZA ONTOLÓGicA

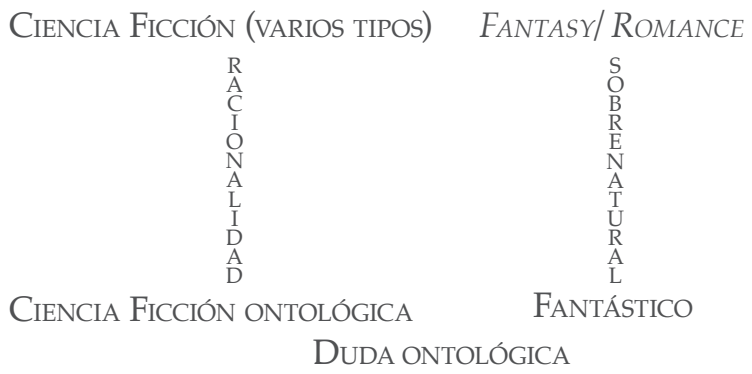


El nuevo diagrama no tendría mayor valor si las categorías propuestas tuvieran sólo existencia teórica y no pudieran ser apoyadas con ejemplos de obras concretas, pero esto no es así. Nos permitimos sostener que para el análisis de una parte importante de la obra de Philip K. Dick, de influencia ineludible en todas las ficciones posteriores centradas en la duda ontológica, la categoría que proponemos de «ciencia ficción ontológica» resulta de suma utilidad.

\section{VIEJAS INQUIETUDES, NUEVOS PARADIGMAS: LA CIENCIA FICCIÓN ONTOLÓGICA}

En su artículo sobre la historia de los géneros literarios, Karl Viëtor (1986: 11) recuerda que ya Robert Hartl afirmaba en 1924 en Versuch einer psychologischen que los géneros expresan una forma de la experiencia del mundo. Todorov (1987: 35), de manera similar, señala que los géneros ponen en evidencia los rasgos constitutivos de la sociedad a la que pertenecen. Puede decirse entonces que lo fantástico fue el producto de un mundo en mutación que no había cambiado durante siglos, al menos en lo que respecta al modelo literario dominante: la concepción mimética de la creación artística, que desterraba lo sobrenatural del ámbito de la literatura. Este modelo, que representaba un mundo inamovible, no resultaba adecuado a una época de transformaciones constantes, cada vez más violentas, que cambiarían para siempre las estructuras sociales, económicas y políticas del mundo occidental. La literatura fantástica, con sus personajes enfrentados a hechos incomprensibles, reflejaba este cataclismo conceptual, manifestación de la incertidumbre del sujeto frente al mundo que lo rodea. Esta primera aparición de relatos de duda ontológica (bajo la forma del relato fantástico) correspondió a un período de grandes cambios paradigmáticos, y su reaparición en el siglo XX parece corresponder a un modelo semejante. Y es que tanto el género fantástico como la «ciencia ficción ontológica» son sintomáticos de lo que Thomas Pavel (1986: 142) llama «estrés ontológico», ${ }^{11}$ causado por dificultades de orientación en situaciones de rápido cambio ontológico, de adaptación a las complejidades de las modificaciones ontológicas modernas. ${ }^{12}$ Cuando nuestra capacidad de

11 Pavel ya utiliza el término en su artículo «Fiction and the ontological landscape» (1982) pero lo desarrolla en Fictional Worlds (1986).

12 En su famosa conferencia «How to Build a Universe That Doesn't Fall Apart Two Days Later», Dick (1995:184) aclara que ve a la duda sobre lo real como problema verdadero y no como una cuestión meramente intelectual. La amenaza estaría entonces constituida por las «realidades espurias» manufacturadas por gobiernos, corporaciones y grupos religiosos, entre ellas los «pseudomundos» enviados «directo a la cabeza» del lector, el oyente o el televidente. El ciudadano común, continúa, está bombardeado así por «pseudorrealidades» a través de mecanismos muy sofisticados (su novela The Three Stigmata of Palmer Eldritch, de hecho, presenta este argumento de manera bastante literal). 
adaptación ontológica se ve superada por la cantidad de cambios es cuando se producen reacciones, que se manifiestan también en la literatura.

Las reacciones generadas por el estrés ontológico, continúa Pavel (1986: 142), pueden variar entre el nihilismo y la nostalgia. Los nihilistas interpretan el cambio de un paisaje ontológico a otro como la prueba de la completa ausencia de orden; los nostálgicos, por el contrario, añoran épocas pasadas en las que la estabilidad ontológica era la regla. Al rechazar la multiplicidad ontológica, los nostálgicos consideran el resto de las ontologías que los rodean como una simple ficción, al menos en comparación con el dogma derribado. ${ }^{13}$ Con respecto a la vertiente literaria de estas reacciones, resulta claro que la fascinación por la Edad Media propia del gótico es claramente una forma de nostalgia. Con su búsqueda desesperada del mundo «real», la ciencia ficción ontológica se muestra igualmente lejos del nihilismo. Pero dado que ambas formas están separadas por más de un siglo y medio, corresponde prestar un poco de atención a otras expresiones literarias vinculadas a lo fantástico.

El aporte principal de Todorov (1970: 24-26) consistió en sistematizar la noción de fantástico, tomando lo que le servía de las definiciones existentes (lo fantástico concebido como una «literatura de la irrupción», en la que un elemento extraño viene a perturbar nuestro sentido de lo real) y reordenándolo en el marco de una teoría precisa de los géneros literarios. La productividad teórica de su texto se hace evidente en las reformulaciones y críticas que generó. Nos interesa aquí en especial la propuesta de Ana González Salvador, que ya en su artículo «Avatars d'un genre: mort ou survie du fantastique?» (1978: 62) postulaba la categoría de «insólito» para definir lo fantástico en el siglo $X X$, un fantástico en el que quizá el lector puede sorprenderse con la irrupción de lo imposible pero el personaje jamás. Y es que de acuerdo con González Salvador, ha habido una evolución en la producción literaria relacionada con la literatura fantástica que no se ha traducido en un cambio en la terminología que enmarca esos textos. Si el objeto ha cambiado, resulta interesante también cambiar de nombre, y de ahí su propuesta de la categoría de «insólito».

En su libro Continuidad de lo fantástico. Por una teoría de la literatura insólita (1980: 55), González Salvador se ocupa extensivamente del concepto de «insólito», para lo cual establece primero los rasgos distintivos de lo fantástico en literatura, que necesitaría un fuerte contenido emocional (casi siempre, la puesta en escena del terror frente a lo sobrenatural) y presentaría bajo diver-

13 La situación de los personajes de las obras catalogables como ciencia ficción ontológica puede verse como una literalización de esta reacción: perdidos en mundos virtuales a los que les niegan existencia, sólo consideran real el mundo que abandonaron y al que desean regresar. 
sas formas la antinomia real/irreal. González Salvador (1980: 58) compara también el relato fantástico con la novela psicológica y la novela de aventuras: un poco a caballo entre ambas, el relato fantástico contaría con un toque de similitud más la presencia de una «parte injustificada». Lo insólito, en cambio, tendría la ventaja de «sugerir lo misterioso sin entrar en la ausencia total de realidad» (González Salvador, 1980: 59). La definición de lo insólito se establecerá entonces sobre una comparación con lo fantástico. Y lo que conservaría de éste es «la duda frente a la realidad como dato coherente, inamovible y tranquilizador» (González Salvador, 1980: 61), sólo que esta duda sería experimentada exclusivamente por el lector, y no tendría correlato intradiegético (la tranquilidad con que se acepta lo insólito en los relatos de Kafka sería un ejemplo de esto). Y es así como serían entonces el narrador y el lector (y no el personaje) los «hacedores de lo insólito» (González Salvador, 1980: 83). Además, el relato insólito tampoco se opondría, como el relato fantástico, a lo familiar (González Salvador, 1980: 88): la visión de la realidad propuesta consistiría en descubrir el lado incoherente de un orden determinado, lejos de la imagen de pérdida de valores tradicionales que constituía el telón de fondo de la literatura fantástica. Por último, González Salvador (1980: 95) señala una diferencia en la mecánica narrativa: en el relato de lo insólito la «técnica de la sorpresa», utilizada por la literatura fantástica, por la novela policíaca o por el surrealismo, sería dejada de lado en beneficio de la «preparación de una expectativa».

La teoría de González Salvador permite resaltar, casi en filigrana y por oposición, el tipo de literatura que queremos definir aquí. Efectivamente, los rasgos que el relato de lo insólito compartiría con la literatura fantástica constituyen casi el exacto opuesto de los que esta literatura compartiría con la ciencia ficción ontológica. Y las diferencias entre las definiciones de «fantástico» e «insólito» residen en la puesta en escena o no de una duda frente a los acontecimientos extraños relatados; en ambos casos, esos acontecimientos deben suceder en el marco de lo que como lectores podemos identificar como el mundo «real», «nuestro» mundo. Esto puede reducirse al esquema siguiente:

MUNDO «REAL»/《NUESTRO MUNDO» + IRRUPCIÓN DE LO IMPOSIBLE + DUDA = FANTÁSTICO

MUNDO «REAL»/ «NUESTRO MUNDO» + IRRUPCIÓN DE LO IMPOSIBLE - DUDA = INSÓLITO

Lo que este cuadro no contempla es una tercera posibilidad, separada de lo fantástico, como lo insólito, por una sola variable: la de un tipo de relato 
en el que un acontecimiento contravenga las reglas de lo posible y en el que esta transgresión esté problematizada, pero en el que las reglas transgredidas no sean las de nuestro mundo sino las de un mundo otro, separado del nuestro por el espacio y/o el tiempo en el que transcurre el relato. El esquema resultante sería el siguiente:

MUNDO «OTRO» + IRRUPCIÓN DE LO IMPOSIBLE + DUDA = - - -

El tipo de relatos así definido está en una relación de continuidad con lo fantástico en lo que respecta a la puesta en escena de una duda sobre la esencia de la realidad; se trata en ambos casos de lo que proponemos llamar «relatos de duda ontológica». Por supuesto, hace tiempo ya que el concepto de «ontología» («Parte de la metafísica que trata del ser en general y de sus propiedades trascendentales», según el DRAE) ha hecho su entrada en la teoría literaria, de la mano de las teorías sobre la ficcionalidad. Thomas Pavel (1981: 234), por ejemplo, define «ontología» como «una descripción teórica de un universo». Y, tomado en ese sentido, es evidente que el concepto resulta pertinente para el análisis literario en su conjunto. Pero lo que a nosotros nos interesa aquí es lo ontológico como atributo de la ficción o, mejor dicho, las ficciones que hacen de lo ontológico su núcleo, problematizando la cuestión ontológica, poniendo en escena una duda sobre la esencia de la realidad.

¿Se puede hablar de ficciones con dominante ontológica y ficciones con dominante epistemológica? ${ }^{14}$ McHale (1999: 59-60) piensa que sí, y afirma entonces que la ciencia ficción, al igual que la ficción posmoderna, está gobernada por la dominante ontológica y que es tal vez el género ontológico por excelencia. ${ }^{15}$ Así, McHale recuerda cómo Darko Suvin definió la ciencia ficción como «literatura del extrañamiento cognitivo», en la que se confrontarían datos empíricos de nuestro mundo con un elemento (o más) ajeno a él, un novum; este extrañamiento sería cognitivo porque eliminaría proyecciones puramente mitopoéticas sin relación alguna con una visión del mundo basada en la lógica, la razón o la ciencia positiva. En este enfrentamiento entre mundos distintos radicaría el énfasis ontológico.

Si bien la clasificación de ficciones según tengan una dominante epistemológica u ontológica puede resultar interesante, la manera en que McHale aplica esta división ha sido criticada por otros autores. Así, Peter Stockwell

\footnotetext{
14 «The dominant may be defined as the focusing component of a work of art: it determines and transforms the remaining components» (Jakobson 1971: 83)

15 Las ficciones con dominante epistemológica serían para McHale (1999: 9) aquellas obras que plantean preguntas ligadas a la interpretación del mundo de la ficción.
} 
señala, en The Poetics of Science-Fiction (2000: 103-104), su desacuerdo en considerar la ciencia ficción como limitada a cuestiones ontológicas. Para Stockwell la ciencia ficción puede tener claramente preocupaciones ontológicas (la obra de Philip K. Dick sería un buen ejemplo de ello), ${ }^{16}$ pero no hay duda de que la epistemología ocupa también un lugar central. El énfasis ontológico que McHale señala en Philip K. Dick correspondería entonces a un cambio de paradigma sucedido en la ciencia ficción, que implicaría un pasaje de la certeza ontológica (necesaria para la exploración epistemológica) a la incertidumbre ontológica (Bukatman 1993: 16). Y también es polémica la afirmación de McHale (1999: 75) de considerar que el consenso en la poética contemporánea se inclina por un acercamiento epistemológico a lo fantástico, acercamiento cuya versión más influyente sería el enfoque de Todorov. ${ }^{17}$ La duda fantástica (esencial para Todorov) sobre la naturaleza de los eventos extraños que tienen lugar en el relato y que afecta en última instancia al universo en que éste sucede (que será o bien natural o bien sobrenatural), no es en última instancia menos ontológica que la duda del personaje dickiano por saber si vive en un mundo material o en uno virtual.

La centralidad de la problemática ontológica en la obra de Dick ha sido señalada por diversos autores: ya Fredric Jameson (1975) habla de la «incertidumbre pesadillesca» (nightmarish uncertainty) debida a la fluctuación de la realidad como rasgo característico. ${ }^{18}$ Mucho más recientemente, y retomando la idea de incertidumbre de Jameson, Umberto Rossi (2011: 6) plantea la incertidumbre ontológica (ontological uncertainty) como elemento clave de la producción dickiana. Rossi comienza la presentación de su concepto, de manera lógica, ofreciendo una definición de «ontología» específica del ámbito del análisis literario: la meditación filosófica sobre la naturaleza del ser, lo existente o la realidad en general (definición básica de ontología), tal y como aparece en una obra de ficción. Y la obra de Dick, continúa Rossi (2011: 10-11), estaría basada en una ontología esencial particularmente inestable, caracterizada por una incertidumbre intradiegética constante, con personajes que no pueden distinguir entre realidad e irrealidad y deben buscar constantemente la realidad oculta por la simulación, a menudo conscientes de que detrás de esa simulación puede haber otra.

16 Vale la pena saber, sin que esto suplante o tenga más valor que la opinión de los analistas (pero en este caso la ratifica), que Dick estaba de acuerdo con este punto de vista. Así, en la conferencia «How to Build a Universe That Doesn't Fall Apart Two Days Later», el autor sostiene que la pregunta sobre qué es la realidad es uno de los tópicos centrales de su obra (Dick 1995: 180).

17 Más allá de su interpretación de Todorov, McHale no deja de considerar que el género fantástico está gobernado por la dominante ontológica (McHale 1999: 74).

18 La versión en línea no contiene números de página. 
La macrocategoría propuesta en este trabajo (relatos de duda ontológica) englobaría tanto al género fantástico según la concepción de Todorov ${ }^{19}$ como a una parte de la producción dickiana, ${ }^{20}$ que correspondería a una ciencia ficción que podemos llamar también ontológica. El rasgo definitorio de este tipo de relatos sería la puesta en escena de una duda sobre la realidad, más allá de la naturaleza del evento disruptivo (sobrenatural, científico, etcétera) y aun de la lógica misma de esta irrupción. En la literatura fantástica, los eventos incomprensibles parecen desafiar las leyes del mundo en que suceden, mientras en la ciencia ficción dickiana son consecuencia del orden mismo que domina el universo ficcional, que es el de lo virtual. ${ }^{21}$ De cualquier modo, es importante tener en cuenta que para que una obra forme parte de la categoría sugerida la duda sobre lo real que se pone en escena debe ser de nivel ontológico. Sin esta última condición estaríamos tratando con otro tipo de obras, en las que no se vulneran las leyes consideradas naturales. ${ }^{22}$

Bibliografía

BERTHELOT, Francis (2006): «Genres et sous-genres dans les littératures de l'imaginaires», disponible en http://www.vox-poetica.org/t/lna/FB\%20Genres\%20imaginaire.pdf [22/01/13].

BozzetTo, Roger (1992): L'obscur objet d'un savoir. Fantastique et Science-Fiction: deux littératures de l'imaginaire, Publications de l'Université de Provence, Aix-enProvence.

19 Rossi (2011: 13) también aclara que su concepto de incertidumbre ontológica también está tomado de Todorov.

20 En distintas conferencias, ensayos o entrevistas, Dick se ha referido a en qué se diferencian (y en qué no) las obras de ciencia ficción y las de géneros con presencia (confirmada o supuesta) de lo sobrenatural. Así, en la entrevista que le realizó Frank C. Bertrand en 1980, Dick (1995: 44) sostiene que lo que distingue a la ciencia ficción de la fantasy (un término que en inglés puede abarcar lo fantástico si se usa en su acepción más común, pudiendo usarse fantastic simplemente como el adjetivo correspondiente) es que los hechos deben respetar las leyes científicas conocidas (algo que su obra no cumple; el supuesto respeto de estas leyes, un efecto generado a través del discurso, sería una definición que correspondería más al género), y por ello no son presentados como imposibles. Sin embargo, en su ensayo «My definition of Science Fiction» (1995: 78), Dick precisa que separar una y otra forma literaria no es realizable, debido a que la percepción de lo que puede llegar a ser posible depende de las creencias del lector.

21 Aunque se trata de un término que se remonta a la filosofía escolástica (Lévy, 1995: 13), el uso que se le da aquí coincide con el propuesto por Denis Berthier (2005: 1) para el contexto de la realidad virtual. Berthier identifica real y material; así, lo virtual pasa a ser aquello que posee todas las cualidades de lo real, sin serlo. La gran ventaja del acercamiento de Berthier es que nos permite entender un elemento recurrente en las ficciones que ponen en escena mundos virtuales: la angustia de los personajes ante la posibilidad de no estar en el mundo real.

22 Estaríamos hablando aquí, por ejemplo, de novelas que presentan en escena la duda sobre lo real $\mathrm{y}$ al tiempo ponen en duda teorías conspirativas. 
Bukatman, Scott (1993): Terminal Identity: The Virtual Subject in Postmodern Science-Fiction, Duke UP, Durham.

Cornwell, Neil (1990): The literary fantastic: from Gothic to posmodernism, Harvester Wheatsheaf, Londres.

DicK, Philip K. (2003 [1964]): The Three Stigmata of Palmer Eldritch, Gollancz, Nueva York.

(1995): The Shifting Realities of Philip K. Dick: Selected Literary and Philosophical Writings (comp. Lawrence Sutin), Vintage/Random House, Nueva York.

FrYe, Northrop (1957): The Anatomy of Criticsm, Princeton University Press, Princeton.

Genette, Gérard (1977): «Genres, “types”, modes», Poétique 32 (1977), pp. 389-421. (1986): «Introduction à l'architexte», en Gérard Genette y Tzvetan Todorov (comps.), Théorie des genres, Éditions du Seuil, París, pp. 89-159.

GonZÁlez SAlVAdor, Ana (1978): «Avatars d'un genre: mort ou survie du fantastique?», en Anuario de Estudios Filológicos (Cáceres) I (1978), pp. 51-64.

(1980): Continuidad de lo fantástico. Por una teoría de la literatura insólita, J.R.S. Editor, Barcelona.

Guillén, Claudio (2005): Entre lo uno y lo diverso, Tusquets, Barcelona.

Hume, Kathryn (1984): Fantasy and Mimesis: responses to reality in Western literature, Methuen, Londres.

JACKSON, Rosemary (1988): Fantasy: the literature of subversion, Methuen, Londres.

JAMESON, Fredric (1975): «After Armageddon: Character Systems in Dr. Bloodmoney», en Science Fiction Studies \# 5 Volume 2, Part 1 (Marzo 1975), disponible en http: / / www.depauw.edu/sfs/backissues/5/jameson5art.htm [22/01/13].

Mc Hale, Brian (1999): Postmodernist Fiction, Routledge, Londres.

PAVEL, Thomas (1981): «Tragedy and the sacred: notes towards a semantic characterization of a fictional genre», Poetics 10, 2-3, pp. 231-242.

(1986): Fictional Worlds, Harvard University Press, Cambridge.

Rossi, Umberto (2011): The Twisted Worlds of Philip K. Dick, Mc Farland, Londres.

SCHAEFFER, Jean-Marie (1986): «Du texte au genre», en Gérard Genette y Tzvetan Todorov (comps.), Théorie des genres, Éditions du Seuil, París, pp. 179-205.

Scholes, Robert (1986): «Les modes de la fiction», en Gérard Genette y Tzvetan Todorov (1986), Théorie des genres, Éditions du Seuil, París, pp. 77-88.

Steimberg, Oscar (1993): Semiótica de los medios masivos, Atuel, Buenos Aires.

Stоcкwell, Peter (2000): The Poetics of Science-Fiction, Longman, Harlow.

Suvin, Darko (1977): Pour une poétique de la science-fiction, Presses de l'Université du Québec (P.U.Q.), Montreal.

Todorov, Tzvetan (1970): Introduction à la littérature fantastique, Éditions du Seuil, París.

(1987): La notion de littérature et autres essais, Éditions du Seuil, París.

VANDENDORPE, Christian (1993): «Pouvoirs du héros et rationalité dans le fantastique et la science-fiction», en Aurélien Boivin, Maurice Émond y Michel Lord (eds.), Les Ailleurs imaginaires, Nuit Blanche, Quebec, pp. 243-263.

VIËTOR, Karl (1986): «L'histoire des genres littéraires», en Gérard Genette y Tzvetan Todorov (comps.), Théorie des genres, Éditions du Seuil, París, pp. 9-35. 